\title{
Cerebral Sinovenous Thrombosis in a Patient with Transient Eosinophilia
}

\author{
Hiroyasu Sano, Takuya Fukuoka, Hajime Maruyama, Takeshi Hayashi and Norio Tanahashi
}

\begin{abstract}
A 67-year-old man with a history of prostatic hypertrophy developed behavioral anomalies and a fever. At admission, diffusion-weighted brain magnetic resonance imaging (MRI) indicated a high-intensity signal lesion on both sides of the cerebral hemisphere. Immediately after hospitalization, he developed paralysis of the left side of the body. Diffusion-weighted MRI indicated hemorrhagic changes in the right and left parietal lobes and right occipital lobe. Magnetic resonance venography indicated superior sagittal sinus occlusion. The blood test results indicated transient eosinophilia. Cases of thrombosis with idiopathic eosinophilia have been reported, but this is the first known case of cerebral sinus thrombosis with transient eosinophilic leukocytosis.
\end{abstract}

Key words: cerebral sinovenous thrombosis, thromboembolism, transient eosinophilia

(Intern Med 53: 2139-2142, 2014)

(DOI: 10.2169/internalmedicine.53.2567)

\section{Introduction}

Eosinophilia is often complicated by thromboembolisms, such as a mural thrombus, cerebral infarction or retinal vessel microthrombus $(1,2)$. In addition, cases of thrombosis in patients with transient eosinophilia have been reported (3-9). In the present report, we describe a case of cerebral sinovenous thrombosis associated with transient eosinophilia; to our knowledge, no such case has previously been reported in the literature.

\section{Case Report}

A 67-year-old man with a history of prostatic hypertrophy presented to a hospital with a slight fever. The patient's white blood cell count was elevated $[16,000 / \mu \mathrm{L}$ (neutrophils 89\%; eosinophils, 3.8\%)] and the C-reactive protein (CRP) level was $17.49 \mathrm{mg} / \mathrm{dL}$. The findings of thoracoabdominal computed tomography (CT) and upper endoscopy were normal.

However, after three days, he was unable to change his clothes and perform calculations. He visited a hospital, and underwent diffusion-weighted brain magnetic resonance im- aging (MRI), which indicated the presence of a highintensity signal lesion in the left temporal lobe, right temporal lobe and right occipital lobe (Fig. 1).

$\mathrm{He}$ was transferred to our department, and exhibited a body temperature of $36.4^{\circ} \mathrm{C}$, blood pressure of $185 / 76$ $\mathrm{mmHg}$, pulse rate of 93 beats/min and significant limb edema on physical examination. His Glasgow Coma Scale score was E4V4M6, and he exhibited a slow verbal response. Moreover, he showed dressing apraxia and acalculia.

The blood test results indicated a red blood cell count of $406 \times 10^{4} / \mathrm{L}$, a hemoglobin level of $15.8 \mathrm{~g} / \mathrm{dL}$, a hematocrit value of $44.6 \%$, a white blood cell count of $14,030 / \mu \mathrm{L}$, a platelet count of $180 \times 10^{3} / \mathrm{L}$ and a percentage of eosinophils of $26.4 \%$. In addition, the levels of CRP, D-dimer and fibrin degradation product-P were $4.69 \mathrm{mg} / \mathrm{dL}, 6.08 \mu \mathrm{g} / \mathrm{mL}$ and $11.9 \mathrm{~g} / \mathrm{mL}$, respectively. During the cerebrospinal fluid examination, we noted that the pressure was $380 \mathrm{mmH}_{2} \mathrm{O}$, the cell count was $1 / \mathrm{mm}^{3}$ and the protein level was $18 \mathrm{mg} / \mathrm{dL}$. Furthermore, the levels of PR3-ANCA, MPO-ANCA, protein $\mathrm{C}$, protein $\mathrm{S}$, antithrombin III and anticardiolipin antibody were normal. The findings of echocardiography were also normal.

However, immediately after hospitalization, the patient exhibited paralysis of the left side of the body, as well as 


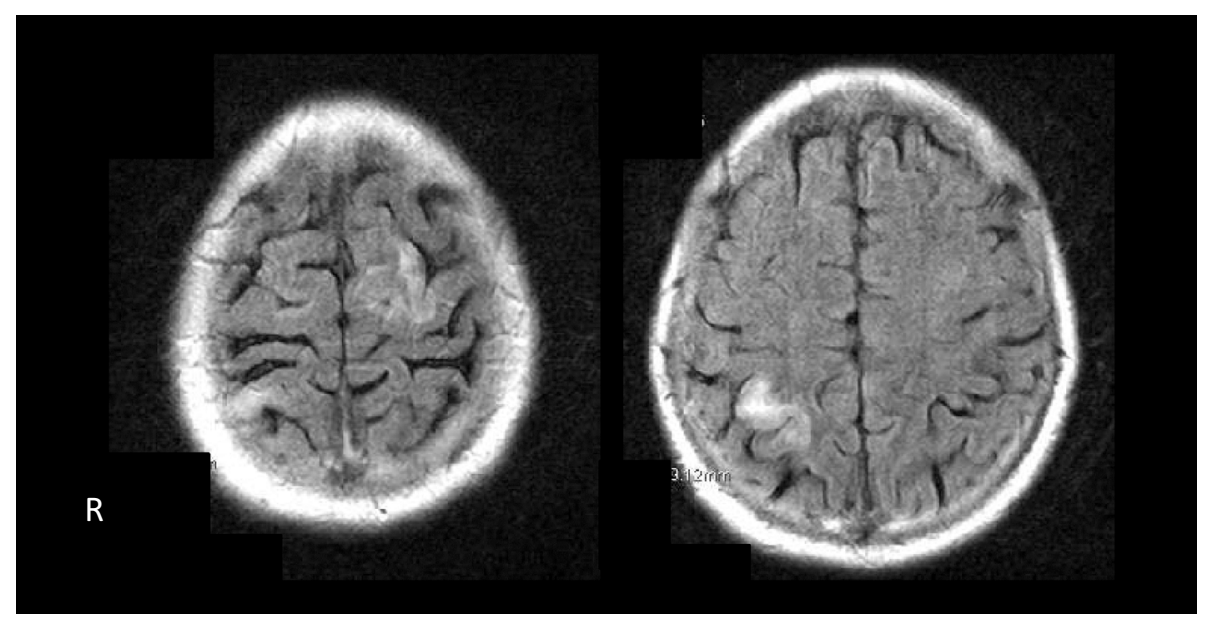

Figure 1. A fluid-attenuated inversion recovery magnetic resonance image of the brain on the admission. Hyperintense areas can be noted in the left temporal lobe and right parietal and occipital lobes.

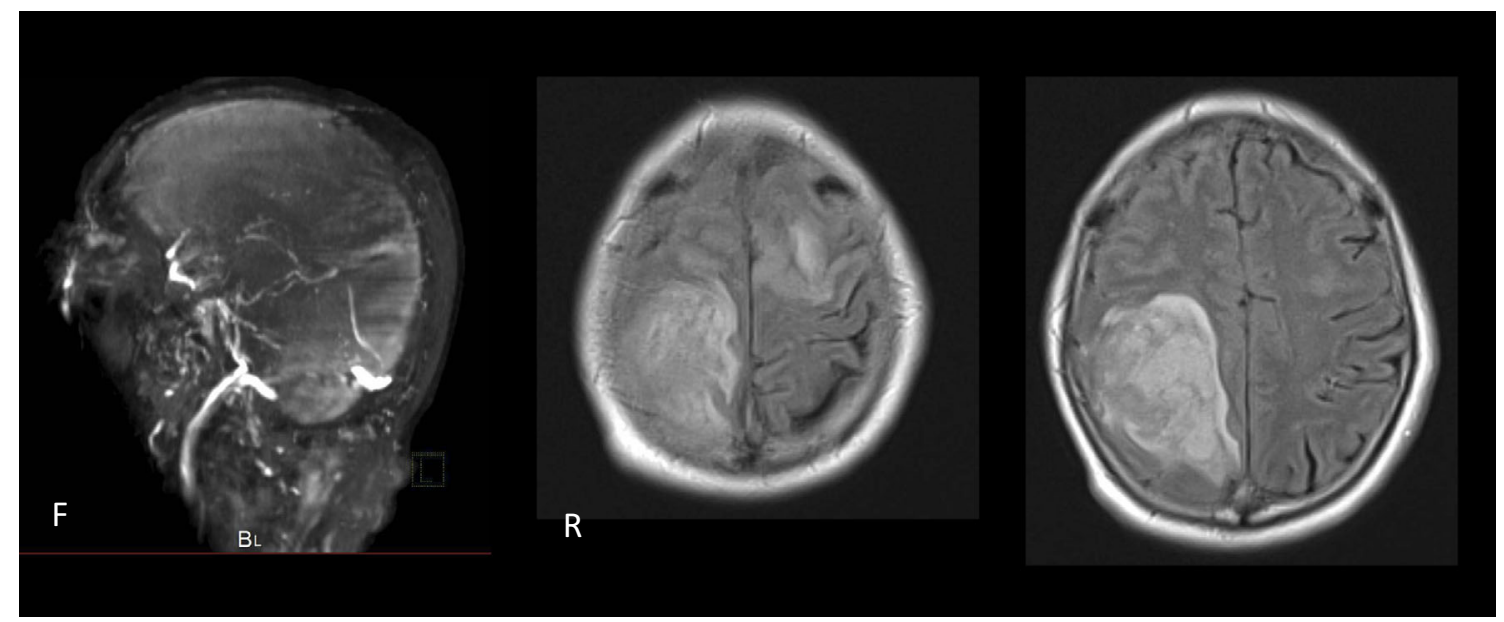

Figure 2. Magnetic resonance venography on admission to our hospital indicated the occlusion of the superior sagittal sinus. A fluid-attenuated inversion recovery magnetic resonance image indicating the presence of hyperintense areas in the right and left parietal lobes and right occipital lobe.

headache and disturbance of consciousness. Fluid-attenuated inversion recovery (FLAIR) MRI of the brain indicated the presence of a hyperintense area in the right and left parietal lobe and right occipital lobe. Magnetic resonance venography indicated occlusion of the superior sagittal sinus (Fig. 2). We diagnosed the patient with hemorrhagic changes, along with thrombosis of the venous sinuses in the brain. On the same day, we performed hematoma removal and cerebral decompression for a right brain hemorrhage. The eosinophil count reached a peak level $(5,130 / \mu \mathrm{L})$ on the fourth day and normalized $(1,018 / \mu \mathrm{L})$ on the fifth day. Treatment with heparin and warfarin was initiated on the fourth day. On the 14th day, magnetic resonance venography still indicated the presence of obstruction at the left transverse sinus and upper sagittal sinus (Fig. 3). However, the D-dimer levels gradually decreased, and showed a reduced level of $0.6 \mu \mathrm{g} / \mathrm{mL}$ on the 33rd day. Although the disturbance of consciousness was also improved, left hemiplegia was still observed and the patient was transferred to another hospital on the 38th day for rehabilitation.

\section{Discussion}

To our knowledge, the present case is the first reported case of cerebral sinovenous thrombosis caused by transient eosinophilia. The causes of cerebral sinovenous thrombosis include drugs, such as oral contraceptives, androgens and danazol; prothrombotic conditions, such as antithrombin III deficiency, protein $\mathrm{C}$ deficiency and protein $\mathrm{S}$ deficiency; infection; cancer-related factors; antiphosholipid and anticardiolipin antibodies and mechanical precipitants (10). None of these causes were observed in the present case. According to Chusid et al, the criteria for hypereosinophilic syndrome include: (1) eosinophilia (1,500 eosinophils $\left./ \mathrm{mm}^{3}\right)$ persisting for more than six months, or death within six months that is associated with the signs and symptoms of hypereosino- 

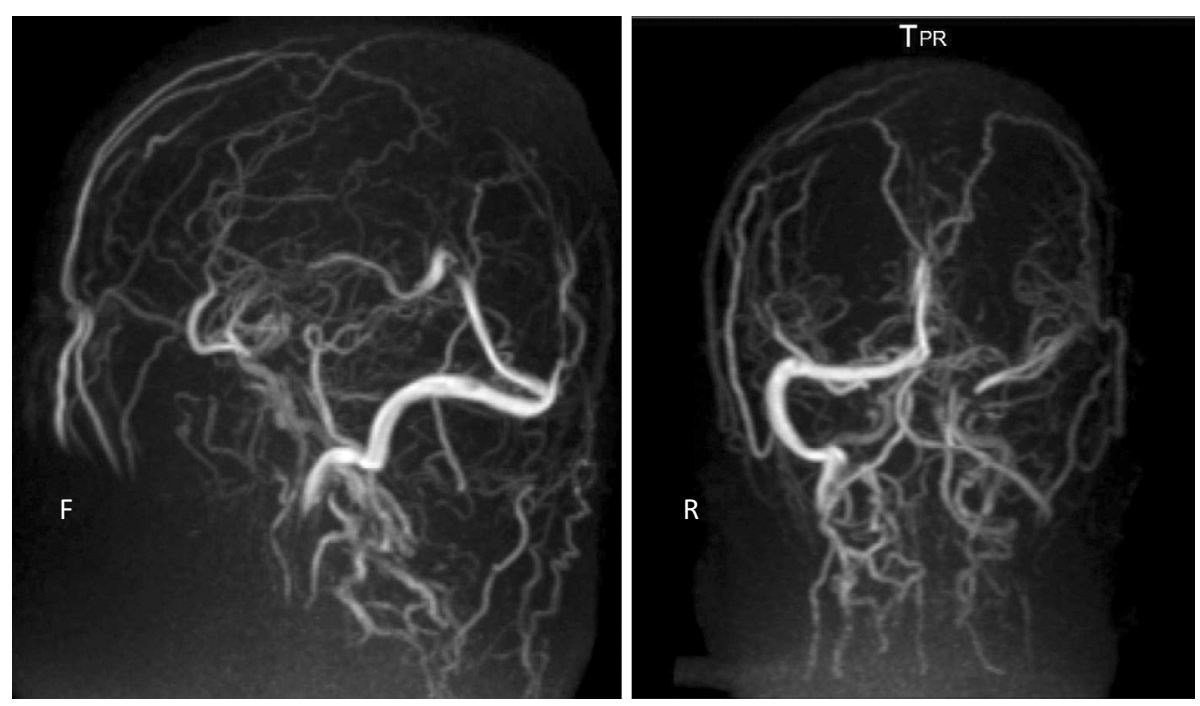

Figure 3. Magnetic resonance venography 14 days after admission indicated that there was occlusion of the transverse sinus and superior sagittal sinus.

Table. Reported Cases of Thromboembolic Events in Patients with Transient Eosinophilia

\begin{tabular}{|c|c|c|c|c|c|c|c|}
\hline Reference & $\begin{array}{c}\text { Age } \\
\text { (years) } \\
\text { /Sex } \\
\end{array}$ & $\begin{array}{c}\text { WBC count } \\
(/ \mu \mathrm{L})\end{array}$ & $\begin{array}{l}\text { Eosinophil } \\
\text { count }(/ \mu \mathrm{L})\end{array}$ & $\begin{array}{c}\% \text { of } \\
\text { Eosinophils }\end{array}$ & $\begin{array}{c}\text { Duration of } \\
\text { eosinophilia (days) }\end{array}$ & Medical history & Organ involvement \\
\hline 3 & $30 / \mathrm{M}$ & 20,000 & 13,300 & 60 & NR & None & Hepatic vein thrombosis \\
\hline 4 & $26 / \mathrm{M}$ & 14,600 & 6,000 & 42 & NR & Ulcerative colitis & Biventricular thrombus, right popliteal artery embolus \\
\hline 5 & $29 / \mathrm{F}$ & 10,400 & 3,120 & 30 & 11 & None & Pulmonary embolism, DVT \\
\hline 6 & $24 / \mathrm{F}$ & 22,800 & 9,350 & 41 & 21 & None & Pulmonary embolism, DVT, hepatic vein thrombosis \\
\hline 7 & 19/M & 18,500 & 8,000 & 40 & NR & Asthma & Pulmonary embolism, DVT \\
\hline 8 & $40 / \mathrm{F}$ & 12,600 & 6,930 & 55 & NR & $\begin{array}{c}\text { Psoriasis, atopic } \\
\text { dermatitis }\end{array}$ & Splenic , portal, and superior mesenteric vein thrombosis \\
\hline 9 & $21 / \mathrm{F}$ & NR & 5,900 & NR & NR & None & Portal and splenic vein thrombosis \\
\hline Present case & $67 / \mathrm{M}$ & 18,320 & 5,130 & 28 & 3 & $\begin{array}{c}\text { Prostatic } \\
\text { hypertrophy }\end{array}$ & Cerebral sinovenous thrombosis \\
\hline
\end{tabular}

NR: not reported, WBC: white blood cells, DVT: deep vein thrombosis

philic disease; (2) a lack of evidence of parasitic, allergic or other known causes of eosinophilia and (3) presumptive signs and symptoms of organ involvement, including hepatosplenomegaly, organic heart murmur, congestive heart failure, diffuse or focal central nervous system abnormalities, pulmonary fibrosis, fever, weight loss and anemia (11). In the present case, the eosinophilia did not persist for more than six months. Therefore, we could not diagnose the patient with hypereosinophilic syndrome.

Idiopathic hypereosinophilic syndrome has been reported to cause thrombosis in the cardiac chamber (12), coronary artery (13), mesenteric artery (14), brachial artery (15), limb vessels (16), hepatic vein (17) and central sinovenous area (18-20). Moreover, seven cases in which thrombosis was caused by transient eosinophilia have been reported (Table). These reports indicate that these thromboses occurred at a relatively young age (range, 19-40 years) and primarily occurred in the hepatic vein, lung vessels, splenic vein, portal vein and popliteal artery.
Thrombomodulin (TM) is known to play a critical role in the anticoagulation system (21). The functional impairment of TM may potentially induce a hypercoagulable state. $\mathrm{Mu}-$ kai et al. reported that mature major basic protein (MBP), which is elevated in the sera of patients with eosinophilia, inhibits the activity of the TM cofactor, thus indicating the potential contribution of eosinophil granule proteins to thrombosis in patients with eosinophilia (22). Thus, we believe that increased levels of eosinophil granule proteins, including MBP, contribute to thrombotic diathesis in patients with eosinophilia. It should be noted that the thrombosis in the present case appear to have been caused by the eosinophilia, even though it only occurred transiently.

The authors state that they have no Conflict of Interest (COI).

\section{References}

1. Fauci AS, Harley JB, Roberts WC, Ferrans VJ, Gralnick HR, 
Bjornson BH. The idiopathic hypereosinophilic syndrome. Ann Intern Med 68: 78-92, 1982.

2. Weller PF, Bubley GJ. The idiopathic hypereosinophilic syndrome. Blood 83: 2759-2779, 1994.

3. Walker M. Idiopathic hypereosinophilia associated with hepatic vein thrombosis. Arch Intern Med 147: 2220-2221, 1987.

4. Koh TW, Coghlan JG, Davarashvilli J, Lipkin DP. thrombus mimicking eosinophilic endomyocardinal disease. Eur Heart J 17: 1770-1771, 1996.

5. Mukai HY, Ninomiya $H$, Mitsuhashi $S$, Hasegawa $Y$, Nagasawa $T$, Abe T. Thromboembolism in a patient with transient eosinophilia. Ann Hematol 72: 93-95, 1996.

6. Sherer Y, Salomon O, Livneh A, Pras M, Langevitz P. Thromboembolism in a patient with transient eosinophilia and thrombocytopenia. Clin Lab Haematol 22: 247-249, 2000.

7. Sade K, Schwartz I, Lev E, Kivity S, Levo Y. Widespread thromboembolism in allergy. Allergy 56: 253-254, 2001.

8. Mates M, Nesher G, Roth B, Rosenberg R, Heyd J, Hershko C. Transient severe eosinophilia precipitating massive venous thrombosis in a patient with hereditary thrombophilia. Acta Haematol 112: 209-211, 2004.

9. Ames PR. Recurrent abdominal thrombosis despite heparin thromboprophylaxis in a patient with transient eosinophilia. Clin Appl Thromb Hemost 17: 229-231, 2011.

10. Saposnik G, Barinagarrementeria F, Brown RD Jr, et al. Diagnosis and management of cerebral venous thrombosis. Stroke 42: 11581192, 2011

11. Chusid MJ, Dale DC, West BC, Wolff SM. The hypereosinophilic syndrome. Medicine 54: 1-27, 1975.

12. Salanitri GC. Endomyocardial fibrosis and intracardiac thrombus occurring in idiopathic hypereosinophilic syndrome. Am J Roentgenol 184: 1432-1433, 2005.
13. Takahashi N, Kondo K, Aoyagi J. Acute myocardial infarction associated with hypereosinophilic syndrome in a young man. Jpn Circ J 61: 803-806, 1997.

14. Kobayashi M, Komatsu N, Kuwayama Y, et al. Idiopathic hypereosinophilic syndrome presenting acute abdomen. Intern Med 46: 675-678, 2007.

15. Ponsky TA, Brody F, Giordano J, Garcia R, Kardon D, Schwartz A. Brachial artery occlusion secondary to hypereosinophilic syndrome. J Vasc Surg 42: 796-799, 2005.

16. Ferguson GT, Starkebaum G. Thromboangiitis obliterans associated with idiopathic hypereosinophilia. Arch Intern Med 145: 1726-1728, 1985.

17. Kojima K, Sasaki T. Veno-occlusive disease in hypereosinophilic syndrome. Intern Med 34: 1194-1197, 1995.

18. Schulman H, Hertzog L, Zirkin H, Hertzanu Y. Cerebral sinovenous thrombosis in the idiopathic hypereosinophilic syndrome in childhood. Pediatr Radiol 29: 595-597, 1999.

19. Sakuta R, Tomita Y, Ohashi M, Nagai T, Murakami N. Idiopathic hypereosinophilic syndrome complicated by central sinovenous thrombosis. Brain Dev 29: 182-184, 2007.

20. Numagami Y, Tomita T, Murakami K, Masaki I, Kubo K, Michiharu N. Sinus thrombosis in idiopathic hypereosinophilic syndrome causing fatal cerebral haemorrhage. J Clin Neurosci 15: 585-587, 2008.

21. Esmon CT, Owen WG. Identification of an endothelialcell cofactor for thrombin-catalyzed activation of protein C. Proc Natl Acad Sci USA 78: 2249-2252, 1981.

22. Mukai HY, Ninomiya $H$, Ohtani $K$, Nagasawa $T$, Abe T. Major basic protein binding to thrombomodulin potentially contributes to the thrombosis in patients with eosinophilia. Br J Haematol 90: 892-899, 1995.

(C) 2014 The Japanese Society of Internal Medicine http://www.naika.or.jp/imonline/index.html 